\title{
PREVALENCE OF POST-EXTUBATION LARYNGOSPASM IN CHILDREN GETTING PROPHYLACTIC INTRAVENOUS LIDOCAINE DURING TONSILLECTOMY - A CROSS SECTIONAL STUDY
}

\author{
Jayakumar Cristhudas ${ }^{1}$, Satheedevi Parameswaran ${ }^{2}$ \\ ${ }^{1}$ Associate Professor, Department of Anaesthesiology, Government Medical College, Manjeri. \\ ${ }^{2}$ Additional Professor, Department of Anaesthesiology, Government Medical College, Manjeri.
}

\section{ABSTRACT}

\section{BACKGROUND}

Tonsillectomy with or without adenoidectomy is one of the most frequent surgical procedures that are carried out globally in children and it is associated with maximum incidence of laryngospasm during extubation. The present study is on prevalence of post-extubation laryngospasm in children getting intravenous lidocaine as prophylaxis.

Objectives - Primary objective is to study the prevalence of laryngospasm in children getting intravenous lidocaine as prophylaxis during extubation following tonsillectomy. Secondary objectives are to study the prevalence of coughing in children getting intravenous lidocaine as prophylaxis during extubation following tonsillectomy and to study the haemodynamic response during extubation in children getting intravenous lidocaine as prophylaxis of post-extubation laryngospasm following tonsillectomy.

\section{MATERIALS AND METHODS}

175 children who were given intravenous lidocaine $2 \mathrm{mg} / \mathrm{kg}$ before extubation after tonsillectomy were studied. The prevalence of laryngospasm, coughing and haemodynamic changes during extubation were studied.

\section{RESULTS}

4 children out of 175 had mild laryngospasm. 18 children had coughing after extubation. 5 children (2.9\%) had mild coughing, 10 children (5.7\%) had moderate coughing and 3 children $(1.7 \%)$ had severe coughing. The prevalence of laryngospasm in our study population is $2.3 \%$. The prevalence of coughing was $10.3 \%$. Heart rate, systolic, and diastolic pressure changes following extubation were compared with pre-extubation values using paired $t$ test. There was no significant change in heart rate, systolic, and diastolic pressure. The $p$ value is more than 0.05 . The oxygen saturation was maintained $>97 \%$.

\section{CONCLUSION}

The prevalence of laryngospasm in children getting intravenous lidocaine as prophylaxis during extubation following tonsillectomy is $2.3 \%$. The prevalence of coughing is $10.3 \%$. There was no significant change in heart rate, systolic, and diastolic pressure and oxygen saturation.

\section{KEYWORDS}

Lidocaine, Laryngospasm, Tonsillectomy.

HOW TO CITE THIS ARTICLE: Cristhudas J, Parameswaran S. Prevalence of post-extubation laryngospasm in children getting prophylactic intravenous lidocaine during tonsillectomy - A cross sectional study. J. Evolution Med. Dent. Sci. 2017;6(5):364-368, DOI: $10.14260 /$ Jemds/2017/83

\section{BACKGROUND}

Tonsillectomy with or without adenoidectomy is one of the most frequent surgical procedures that are carried out globally in children. Although it is a common procedure, it presents risks and challenges for both the surgeon and the anaesthetist. Tonsillectomy is an elective procedure with more than average mortality approximately 1 per 10-20000 cases.(1) Children had a twofold higher incidence of fatal respiratory events in the postoperative period.

In a study conducted by Brown. K. A in 2011 in children undergoing adenotonsillectomy, $44 \%$ of mortality or

Financial or Other, Competing Interest: None.

Submission 11-12-2016, Peer Review 03-01-2017,

Acceptance 10-01-2017, Published 16-01-2017.

Corresponding Author:

Dr. Jayakumar Cristhudas,

Associate Professor,

Department of Anaesthesiology,

Government Medical College,

Manjeri, Malappuram (Dist.),

Kerala.

E-mail: drjkanaesthesia@gmail.com

DOI: $10.14260 /$ jemds $/ 2017 / 83$

\section{(c) $(i)$}

profound brain injury resulted from postoperative respiratory complications.(2) Among the respiratory causes of cardiac arrest, airway obstruction from laryngospasm was $6 \%$. Laryngospasm is a serious complication which was the most common seen in anaesthesia during induction, intubation or extubation. It is a frequently encountered complication in children undergoing upper airway surgery which if left untreated can lead to an increase in morbidity and mortality. The reported incidence of laryngospasm in patients aged $0-9$ years is $17.4 \%$ and is even higher in children between 1 and 3 months of age.(3)

The incidence of laryngospasm after adenoidectomy and tonsillectomy is reported to be as high as $21-26 \%$.(4) Children are more prone to airway obstruction as they have a narrow laryngeal and tracheal lumen that may be blocked by mucosal oedema.(5) The complications resulting from laryngospasm are cardiac arrest $0.5 \%$, obstructive negative pressure pulmonary oedema $4 \%$, pulmonary aspiration $3 \%$, bradycardia $6 \%$ and oxygen desaturation $61 \%$.(6) Various techniques to prevent or treat laryngospasm include intravenous lidocaine which is easily available in operation theatre and cheaper. It has an additional advantage of blunting pressor response during laryngoscopy and intubation. 
Its side effects are dose related and not seen at plasma concentration less than $5 \mu \mathrm{g} / \mathrm{mL}$. The present study aims at the efficacy of a commonly available drug lidocaine in preventing laryngospasm. The primary outcome of our study is prevalence of post-extubation laryngospasm in children getting IV lidocaine as prophylaxis. We also study the prevalence of coughing in children getting IV lidocaine during extubation and also the haemodynamic changes associated with extubation.

\section{Aim of Study \\ Objectives}

Primary objective was to study the prevalence of laryngospasm in children getting intravenous lidocaine as prophylaxis during extubation following tonsillectomy.

\section{Secondary}

1. To study the prevalence of coughing in children getting intravenous lidocaine as prophylaxis during extubation following tonsillectomy

2. To study the haemodynamic response during extubation in children getting intravenous lidocaine as prophylaxis of post-extubation laryngospasm following tonsillectomy.

\section{MATERIALS AND METHODS}

The study was conducted in 175 children undergoing tonsillectomy with or without adenoidectomy aged between 3 and 12 years in the Department of Anaesthesiology, Government Medical College Trivandrum. Informed written consent from patients was taken. Result values were recorded using a pre-set proforma.

\section{Study Design}

Cross sectional study to study the prevalence of laryngospasm in children getting intravenous lidocaine as prophylaxis during extubation following tonsillectomy.

\section{Study Population}

Children getting IV lidocaine before extubation while undergoing tonsillectomy and satisfying inclusion and exclusion criteria.

\section{Inclusion Criteria}

a. Children in the age 3-12 years.

b. ASA I-II

\section{Exclusion Criteria}

Children with history of

a. Congenital heart disease.

b. Bronchial asthma.

c. Recent respiratory tract infection.

\section{MATERIALS AND METHODS}

After obtaining the approval from the hospital ethical community and the written informed consent from the patients, the study was conducted at Government Medical College, Trivandrum. Children with 3-12 years of age undergoing tonsillectomy and satisfying inclusion and exclusion criteria were included in the study. Informed written consent was taken from parents after explaining details of the study. Noninvasive monitors such as pulse oximeter, ECG, automated non-invasive blood pressure and end tidal $\mathrm{CO} 2$ monitor were used. All children had an appropriate sized IV cannula. The children were preoxygenated with $100 \%$ oxygen for 3 minutes and then premedicated with Inj. Atropine $0.02 \mathrm{mg} / \mathrm{kg}$ IV, Inj. Midazolam $0.02 \mathrm{mg} / \mathrm{kg}$ IV and Inj. Metoclopramide $0.2 \mathrm{mg} / \mathrm{kg}$ IV. General anaesthesia was induced with Sevoflurane 1-2\%, Inj. Propofol $2 \mathrm{mg} / \mathrm{kg}$ IV, Inj. Fentanyl $2 \mu \mathrm{g} / \mathrm{kg}$ IV and Inj. Vecuronium $0.1 \mathrm{mg} / \mathrm{kg}$ IV and intubated with appropriate size RAE tube. Anaesthesia was maintained with Sevoflurane $2 \%$, Nitrous oxide $60 \%$ and oxygen $40 \%$ and IPPV. The neuromuscular blockade was antagonised with Inj. Neostigmine $0.05 \mathrm{mg} / \mathrm{kg}$ and Inj. Atropine $0.02 \mathrm{mg} / \mathrm{kg}$. The heart rate, blood pressure and oxygen saturation 3 minutes after reversal is noted. 3 minutes after reversal IV lidocaine 2 $\mathrm{mg} / \mathrm{kg}$ was given and the haemodynamic parameters like heart rate, systolic and diastolic blood pressures were noted. Then, children were ventilated with $100 \%$ oxygen for 90 seconds and then children were extubated. After extubation $100 \% \mathrm{O}_{2}$ was given for 3 minutes and then $40 \% 02$ through venture face mask. For 10 minutes following extubation, heart rate, blood pressure, oxygen saturation, breathing pattern, severity of coughing and laryngospasm were noted.

Coughing was evaluated using the modified four-point scale: $0=$ None, $1=$ Slight, $2=$ moderate, $3=$ severe .

Laryngospasm was graded using the four-point scale: $0=$ No laryngospasm, $1=$ Stridor during inspiration, $2=$ Total occlusion of cords, 3=Cyanosis. Cases with laryngospasm were immediately treated by giving positive pressure ventilation with $100 \% \mathrm{O}_{2}$, jaw thrust and Inj. Propofol 0.5 $\mathrm{mg} / \mathrm{kg}$. The haemodynamic parameters heart rate, blood pressures and $\mathrm{O}_{2}$ saturation were monitored at 1-minute interval for 10 minutes after Extubation.

$$
\begin{aligned}
& \text { Sample Size: } \mathrm{n}=\left(\mathrm{Z}_{1-\alpha}\right)^{2}\left(\mathrm{P}(1-\mathrm{P}) / \mathrm{D}^{2}\right) \\
& \begin{aligned}
& \mathrm{Z}_{1-\alpha}=\mathrm{Z}_{0.90}=1.645 \\
& \mathrm{n}=1.645 \times 1.645\left(0.20(1-0.20) / 0.05^{2}\right) \\
&=173.1856 \\
& \mathrm{~N}=175
\end{aligned}
\end{aligned}
$$

\section{Statistical Analysis}

Data were analysed using computer software Statistical Package for Social Sciences (SPSS) latest version. Data were expressed in its frequency and percentage as well as mean and standard deviation. Paired t test was used to compare pre-extubation mean value and value at 1-10 minutes after extubation.

\section{RESULTS}

\begin{tabular}{|c|c|c|}
\hline Age in Years & Frequency & Percentage \\
\hline 3 & 9 & 5.1 \\
\hline 4 & 6 & 3.4 \\
\hline 5 & 14 & 8 \\
\hline 6 & 42 & 24 \\
\hline 7 & 42 & 24 \\
\hline 8 & 12 & 6.9 \\
\hline 9 & 13 & 7.4 \\
\hline 10 & 8 & 4.6 \\
\hline 11 & 13 & 7.4 \\
\hline 12 & 16 & 9.1 \\
\hline Total & $\mathbf{1 7 5}$ & $\mathbf{1 0 0}$ \\
\hline \multicolumn{2}{|c|}{ Table 1. Age Distribution of Study Groups } \\
\hline \multicolumn{2}{|c}{}
\end{tabular}




\begin{tabular}{|c|c|c|}
\hline Sex & Frequency & Percentage \\
\hline Female & 55 & 31.4 \\
\hline Male & 120 & 68.6 \\
\hline Total & $\mathbf{1 7 5}$ & $\mathbf{1 0 0}$ \\
\hline \multicolumn{2}{|c|}{ Table 2. Sex distribution of Study Groups } \\
\hline
\end{tabular}

\begin{tabular}{|c|c|c|c|c|c|}
\hline & N & Min & Max & Mean & Std.Deviation \\
\hline Age in years & 175 & 3 & 12 & 7.40 & 2.41 \\
\hline Weight in KG & 175 & 15 & 45 & 24.31 & 8.66 \\
\hline Dose (Minimum) & 175 & 30 & 120 & 70.54 & 22.98 \\
\hline \multicolumn{2}{|c|}{ Table 3. Table showing Mean Age, } \\
Weight and Duration of Surgery \\
\hline
\end{tabular}

The mean weight of children was $24.3 \mathrm{Kg}$ and the mean duration of surgery was 70 minutes.

\begin{tabular}{|c|c|c|c|}
\hline Laryngospasm & Frequency & Percentage & $\mathbf{9 5 \%}$ CI \\
\hline Absent & 171 & 97.7 & \\
\hline Grade1 & 4 & 2.3 & $0.8-5.7 \%$ \\
\hline Grade 2 & 0 & 0 & \\
\hline Grade 3 & 0 & 0 & \\
\hline Total & $\mathbf{1 7 5}$ & $\mathbf{1 0 0}$ & \\
\hline \multicolumn{4}{|c|}{ Table 4. Frequency and Percentage of Laryngospasm }
\end{tabular}

The prevalence of laryngospasm in our study population was $2.3 \%$ with a $95 \%$ CI between $0.8-5.7 \%$.

\begin{tabular}{|c|c|c|}
\hline Coughing & Frequency & Percentage \\
\hline Absent & 157 & 89.7 \\
\hline Grade1 & 5 & 2.9 \\
\hline Grade2 & 10 & 5.7 \\
\hline Grade 3 & 3 & 1.7 \\
\hline Total Children with coughing & 18 & 10.3 \\
\hline \multicolumn{2}{|c|}{ Table 5. Frequency and Percentage of Coughing } \\
\hline
\end{tabular}

18 children had coughing after extubation, 5 children had mild coughing, 10 had moderate coughing and 3 children had severe coughing.The prevalence of coughing was $10.3 \%$ with a 95\% CI between $6.38-16.01 \%$. 89.7\% of children did not have coughing after extubation.

\begin{tabular}{|c|c|c|c|c|c|c|}
\hline & \multirow{2}{*}{$\mathbf{N}$} & \multicolumn{2}{|c|}{ Heart Rate } & \multicolumn{3}{|c|}{ Paired Comparison with base Line Value } \\
\hline & & Mean & SD & Mean difference & Se & $\mathbf{P}$ \\
\hline HR pre & 175 & 102.42 & 10.316 & & & \\
\hline HR 1 & 175 & 102.65 & 10.275 & 0.229 & 0.132 & 0.085 \\
\hline HR 2 & 175 & 102.66 & 10.439 & 0.240 & 0.144 & 0.097 \\
\hline HR 3 & 175 & 102.60 & 10.373 & 0.177 & 0.120 & 0.141 \\
\hline HR 4 & 175 & 102.57 & 10.327 & 0.143 & 0.079 & 0.072 \\
\hline HR 5 & 175 & 102.54 & 10.323 & 0.114 & 0.066 & 0.084 \\
\hline HR 6 & 175 & 102.44 & 10.352 & 0.017 & 0.059 & 0.771 \\
\hline HR 7 & 175 & 102.47 & 10.251 & 0.051 & 0.071 & 0.727 \\
\hline HR 8 & 175 & 102.35 & 10.314 & 0.074 & 0.085 & 0.386 \\
\hline HR 9 & 175 & 102.29 & 10.19 & 0.137 & 0.105 & 0.195 \\
\hline HR 10 & 175 & 102.22 & 10.16 & 0.200 & 0.200 & 0.139 \\
\hline \multicolumn{7}{|c|}{ Table 6. Changes in Heart Rate Following Extubation } \\
\hline
\end{tabular}

\begin{tabular}{|c|c|c|c|c|c|c|}
\hline & \multirow{2}{*}{$\mathbf{N}$} & \multicolumn{2}{|c|}{ SBP } & \multicolumn{3}{|c|}{ Paired Comparison with Baseline Value } \\
\hline & & Mean & SD & Mean Difference & Se & $\mathbf{P}$ \\
\hline SBP PRE & 175 & 102.99 & 5.217 & & & \\
\hline SBP1 & 175 & 103.28 & 5.361 & 0.286 & 0.152 & 0.061 \\
\hline SBP2 & 175 & 103.26 & 5.392 & 0.263 & 0.149 & 0.080 \\
\hline SBP3 & 175 & 103.15 & 5.518 & 0.160 & 0.126 & 0.206 \\
\hline SBP4 & 175 & 103.10 & 5.372 & 0.103 & $0 .-089$ & 0.250 \\
\hline SBP 5 & 175 & 102.93 & 5.299 & 0.069 & 0.087 & 0.432 \\
\hline SBP6 & 175 & 102.96 & 5.317 & 0.034 & 0.112 & 0.759 \\
\hline SBP7 & 175 & 102.98 & 5.247 & 0.011 & 0.111 & 0.918 \\
\hline SBP8 & 175 & 102.88 & 5.285 & 0.114 & 0.118 & 0.333 \\
\hline SBP9 & 175 & 102.82 & 5.284 & 0.171 & 0.116 & 0.140 \\
\hline SBP10 & 175 & 102.78 & 5.194 & 0.217 & 0.144 & 0.132 \\
\hline
\end{tabular}




\begin{tabular}{|c|c|c|c|c|c|c|}
\hline & \multirow{2}{*}{$\mathbf{N}$} & \multicolumn{2}{|c|}{ DBP } & \multicolumn{3}{|c|}{ Paired Comparison with Base Line Value } \\
\hline & & Mean & SD & Mean Difference & Se & $\mathbf{P}$ \\
\hline DBP Pre & 175 & 66.17 & 3.982 & & & \\
\hline DBP1 & 175 & 66.47 & 4.45 & 0.297 & 0.163 & 0.07 \\
\hline DBP2 & 175 & 66.45 & 4.197 & 0.274 & 0.149 & 0.067 \\
\hline DBP3 & 175 & 66.14 & 4.21 & 0.034 & 0.122 & 0.779 \\
\hline DBP4 & 175 & 66.14 & 3.975 & 0.034 & 0.103 & 0.74 \\
\hline DBP5 & 175 & 66.34 & 3.985 & 0.171 & 0.105 & 0.104 \\
\hline DBP6 & 175 & 66.31 & 3.968 & 0.137 & 0.103 & 0.186 \\
\hline DBP7 & 175 & 66.19 & 4.027 & 0.023 & 0.11 & 0.836 \\
\hline DBP8 & 175 & 65.98 & 3.812 & 0.194 & 0.128 & 0.132 \\
\hline DBP9 & 175 & 65.95 & 3.959 & 0.217 & 0.116 & 0.064 \\
\hline DBP10 & 175 & 65.95 & 3.977 & 0.217 & 0.122 & 0.076 \\
\hline \multicolumn{7}{|c|}{ Table 8. Changes in Diastolic BP during Extubation } \\
\hline
\end{tabular}

\begin{tabular}{|c|c|c|c|}
\hline & \multirow{2}{*}{$\mathbf{N}$} & \multicolumn{2}{|c|}{ SPO2 } \\
\cline { 3 - 4 } & & Mean & SD \\
\hline SPO2 1 & 175 & 97.91 & 0.83 \\
\hline SPO2 2 & 175 & 98.02 & 0.77 \\
\hline SPO2 3 & 175 & 98.12 & 0.77 \\
\hline SPO2 4 & 175 & 98.57 & 0.68 \\
\hline SPO2 5 & 175 & 98.89 & 0.45 \\
\hline SPO2 6 & 175 & 99.09 & 0.45 \\
\hline SP02 7 & 175 & 99.15 & 0.36 \\
\hline SPO2 8 & 175 & 99.47 & 0.5 \\
\hline SPO2 9 & 175 & 99.47 & 0.5 \\
\hline SPO2 10 & 175 & 99.69 & 0.46 \\
\hline \multicolumn{3}{|c|}{ Table 9. Change in SPO2 following Extubation } \\
\hline
\end{tabular}

\section{DISCUSSION}

Tonsillectomy with or without adenoidectomy is a common procedure in children. But it is associated with highest incidence (20-26\%) of laryngospasm. Various measures for prevention and treatment of laryngospasm have been studied. This study was a cross sectional study carried out at Government Medical College Trivandrum. 175 children in the age group 3-12 years (ASA I and II) scheduled for tonsillectomy with or without adenoidectomy were included in this study. Children with history of respiratory tract infection within 4 weeks and history of asthma were excluded from the study. Children were anaesthetised with Sevoflurane, Propofol and Vecuronium and intubated with RAE tubes of appropriate size. At the end of the procedure, 3 minutes after reversal, IV lidocaine $2 \mathrm{mg} / \mathrm{kg}$ was given and 90 seconds later the children were extubated. Then, the prevalence of laryngospasm, coughing, changes in blood pressure, heart rate and 02 saturation after extubation were studied. In our study, children in the age group 5-7 years constituted $56 \%$. This is in agreement with the study by J. Aleeson Glover - "The Incidence of Tonsillectomy in School children". According to him, the highest incidence is in the period 5-7 years, the peak being in the $6^{\text {th }}$ year.

Our study group included $68.6 \%$ boys and $31.4 \%$ girls. According to study by Glover JA, the incidence of tonsillectomy is higher in boys than in girls.(7) In our study, in 175 children who got IV Lidocaine $2 \mathrm{mg} / \mathrm{kg} 90$ seconds before extubation, only 4 children $(2.3 \%)$ had laryngospasm. This laryngospasm was mild and easily treated with $100 \%$ 02, positive pressure ventilation and propofol. According to study by Baraka et al, IV Lidocaine controls extubation laryngospasm in children. Intravenous Lidocaine $2 \% 2 \mathrm{mg} / \mathrm{kg}$ given 60 seconds before extubation reduced the incidence of laryngospasm to $0 \%$ from $20 \%$ in children undergoing tonsillectomy. $(8)$
In our study, the 18 children out of 175 developed postextubation coughing. The prevalence of coughing in children getting IV lidocaine during extubation was $10.3 \%$. Out of 18 children, 5 (2.9\%) had mild coughing, 10 (5.7\%) had moderate coughing and $3(1.7 \%)$ had severe coughing. According to study by Yukioka $\mathrm{H} \mathrm{Et} \mathrm{al,} \mathrm{IV} \mathrm{lidocaine} \mathrm{is} \mathrm{a} \mathrm{cough}$ suppressant during tracheal intubation in elderly patients and incidence of coughing after giving $2 \mathrm{mg} / \mathrm{kg}$ lidocaine IV 1 minute before intubation was $10 \%$. In their $2^{\text {nd }}$ study, the incidence of coughing was only $7 \%$ with the same dose of lidocaine given 1 minute before intubation.(9)

A previous study by Bidwai and colleagues also showed decreased incidence of coughing after giving lidocaine before extubation and the dose given was $1 \mathrm{mg} / \mathrm{kg} 2 \%$ Lidocaine IV 2 minutes prior to extubation. This prevented significant change in BP, heart rate and reduced coughing. ${ }^{(10)}$

Study by CS Sanikop et al showed that IV Lidocaine produced little increase in heart rate and BP compared to placebo and also did not produce fall in SPO2 after extubation in children who got lidocaine before extubation.(11) These results were similar to our study.

\section{CONCLUSION}

The prevalence of laryngospasm in children undergoing tonsillectomy and getting IV lidocaine during extubation was $2.3 \%$. It was much less than the usual incidence of laryngospasm $20-26 \%$ in children undergoing tonsillectomy. The prevalence of coughing in children getting IV lidocaine during extubation is $10.3 \%$. There was no significant change in heart rate, systolic or diastolic blood pressure. The $\mathrm{P}$ value was more than 0.05 . The oxygen saturation (SPO2) was maintained at $>97 \%$. There was no fall in SPO2 after extubation.

\section{REFERENCES}

[1] Raeder J. Ambulatory anaesthesia aspects for tonsillectomy and abrasion in children. Current Opinion In Anaesthesiology 2011;24(6):620-6.

[2] Brown KA. Outcome risk and error and the child with obstructive sleep apnea. Paediatr Anaesth 2011;21(7):771-80.

[3] Roy WL, Lerman J. Laryngospasm in paediatric anaesthesia. Canadian Journal of Anaesthesia 1988;35(1):93-8.

[4] Visvanathan T, Kluger MT, Webb RK, et al. Crisis management during anaesthesia: laryngospasm. Quality \& Safety in Health Care 2005;14(3):e3. 
[5] Gulhas N, Durmus M, Demirbilek S, et al. The use of magnesium to prevent laryngospasm after tonsillectomy and adenoidectomy: a preliminary study. Paediatric Anesthesia 2003;13(1):43-7.

[6] Ray M, Saha E. Complications following general anaesthesia in paediatric patients. Indian Journal of Anaesthesia 2004;48(5):400-5.

[7] Glover JA. The incidence of tonsillectomy in school children. 1938. International Journal Epidemiology 2008;37(1):9-19.

[8] Barak A. Intravenous lidocaine controls extubation laryngospasm in children. Anesthesia Analgesia 1978;57(4):506-7.
[9] Yukioka H, Hayashi M, Terai $T$, et al. Intravenous lidocaine as a suppressant of coughing during tracheal intubation in elderly patients. Anesthesia Analgesia 1993;77(2):309-12.

[10] Bidwai AV, Bidwai VA, Rogers CR, et al. Blood pressure and rate responses to endotracheal extubation with and without prior injection of lidocaine. Anesthesiology 1979;51(2):171-3.

[11] Sanikop CS, Bhat S. Efficacy of intravenous lidocaine in prevention of post extubation laryngospasm in children undergoing cleft palate surgeries. Indian Journal of Anesthesia 2010;54(2):132-6. 